\title{
LA OBRA DE NICOLÁS FERNÁNDEZ DE MORATÍN REVISADA POR SU HIJO LEANDRO: EL AUTÓGRAFO DE LAS OBRAS PÓSTUMAS CONSERVADO EN LA BIBLIOTECA MADRILEÑA DE BARTOLOMÉ MARCH
}

\author{
Belén TEJERINA \\ Universidad de Padua
}

Entre los manuscritos que posee Bartolomé March en su Biblioteca madrileña (BBMM) hay tres manuscritos autógrafos de Leandro Fernández de Moratín que queremos señalar': la silva que dedicó "A don Francisco de Goya" [Quise aspirar a la segunda vida $]^{2}$, dos cartas dirigidas a Juan Grassot $^{3}$, director de la casa de comercio de Barcelona de este nombre y los folios que entregó a la imprenta de la Viuda de Roca de Barcelona para publicar la edición de las Obras Póstumas de su padre, Nicolás Fernández de Moratín ${ }^{4}$, muerto en Madrid el 11 de Mayo de 1780. No hará falta recordar que la primera edición de las Obras Póstumas (OP) apareció en Barcelona en 1821 (Fernández de Moratín,

1. Aguilar Piñal. 1983, los registra así n" 3383, pág. 406: "Fragmentos de las obras de D. ...: La Hormesinda, Guzmán el Bueno, Lucrecia, La Diana o Arte de la Caza. Copia hecha por su hijo Leandro, conteniendo correcciones inéditas, también autógrafas, de este último. [s.a] 40 hojas $23 \mathrm{~cm}$.", y en el n" 2641, pág. 342, dedicado a Leandro: "Poesías originales autógrafas, [s.a.], fols. 45-93. Cedidos por el impresor de sus obras en Barcelona, Agustín Roca".

2. Un folio $(30 \times 20 \mathrm{~mm}$.), en el ángulo superior derecho se lee en un sello en seco: "De la colección de autógrafos de Claudio Rodríguez Porrero". Está fechado en "Burdeos el 13 de Octubre año de 1824". Lleva la firma autógrafa de Leandro Fernández de Moratín, BBMM, Colección de autógrafos, pensamientos, poesía lirica y dramática. Siglos XVIII al XX, 17/9/1 (I), ms. 787, fol. 40. La silva no presenta ninguna variante con la publicada por L. Fernández de Moratín. 1825, III, pp. 454-455; hemos consultado el ejemplar corregido por el autor que se conserva en la BNM, R. 2573.

3. Las acaba de publicar R. de la Fuente Ballesteros (1988). Con el fin de poder utilizar estas cartas en estudios futuros, nos parece oportuno señalar la signatura bajo la que se conservan en la BBMM por faltar en dicho artículo, Personalidades de las letras españolas, correspondencia de los siglos XVIII al $X X, 18-9-1$ (II), ms. 108 .

4. Sobre la vida y obra de Don Nicolás véanse: la tesis de N. Juárez, 1979; la monografía de D. Thatcher Gies, 1980, y el número monográfico dedicado a Moratín padre de la Revista de Literatura, 84 (1980). 
Nicolás, 1821) en dicha Imprenta y en 1825 en Londres en la Imprenta de M. Calero (Fernández de Moratín, Nicolás, 1825).

Está ya demostrada la labor de corrección que realizó Moratín hijo en las tan conocidas y recitadas quintillas que Moratín padre dedicara a la Fiesta de toros en Madrid (Lázaro Carreter, 1953, pp.33-38), publicadas por primera vez en las OP (pp. 78-93); correcciones semejantes sufrió también la edición póstuma de Las naves de Cortés destruidas (Dowling, 1977, pp. 431-483), el Canto épico que don Nicolás presentó al Certamen literario convocado por la Real Academia española en 1777 y que quedó inédito al no conseguir ni siquiera el accésit. Se publicó póstumo en 1785 acompañado de un prólogo y de algunas reflexiones críticas (Fernández de Moratín, Nicolás, 1785).

No es extraño, como ya se ha supuesto, que esta labor de poda y corrección se haya extendido a toda la producción paterna presente en las OP.

El que los talleres de la imprenta de la Viuda de Roca hayan utilizado, para componer la edición de las OP, este manuscrito autógrafo de Leandro en lugar del autógrafo de don Nicolás nos plantea el problema de la autoría de las correcciones. Ante este autógrafo nos tenemos que preguntar si se trata de una copia fidedigna del ms, que según cuenta Leandro en las $\mathrm{OP}$, don Nicolás había entregado a su amigo Bernascone, o si, por el contrario, es el original autógrafo que Leandro preparó para la edición.

El hallazgo de este manuscrito autógrafo de Leandro puede servir para llegar a una conclusión distinta de la que Moratín hijo quiere hacernos creer en las OP y para poner en claro cuál ha sido realmente la tarea del hijo al publicar la obra póstuma del padre; para esto tenemos que tener en cuenta los objetivos que el hijo perseguiría como editor de las OP y los criterios con que realizó las numerosas correcciones y omisiones que presentan los textos de don Nicolás seleccionados en las OP. Es necesario integrar y comparar lo que dice en las OP con lo que él cuenta a sus amigos en algunas cartas. Su Epistolario (Andioc, 1973), $\tan$ rico en noticias y episodios biográficos, puede ayudar a esclarecer este problema. Allí cuenta los hechos tal y como sucedieron. Por el contrario, en las $\mathrm{OP}$, tanto en la "Vida del Autor" como en la nota "Al Lector", falsea algunas noticias en función de sus propios intereses, como veremos luego; son, por tanto, documentos no creíbles en donde aparecen los hechos tal y como a él le hubieran gustado que sucediesen.

Es evidente que Leandro quiere que las OP sirvan para que el poeta Nicolás Moratín pase a la posteridad según la estima que él creía y quería que se le otorgase. Opinión que no dejará de recordar en una frase que aparece en una de las muchas cartas que nos ha dejado en su relación epistolar con su amigo Melón, escrita en Montpellier, el 18 de Octubre de 1817: "en quanto a su mérito (para evitar cotejos odiosos), te aseguro que fue el mejor poeta del reynado de Carlos tercero; y esto nadie me lo podrá contradecir" (Andioc, 1973, pág. 380). 
El amor filial que Leandro profesaba a su padre, tan diferente a él por temperamento e ingenio, revela agradecimiento y una mezcla de admiración humana y/o poética. Es esta admiración y agradecimiento lo que le inspiraría el deseo de honrar su nombre haciendo lo posible porque pasara a la posteridad como figura clave de la reforma de la poesía española y obtuviera así el tributo que la república de las letras, a su juicio, le debía. En la última estrofa de la oda que dedicó A la memoria de don Nicolás Fernández de Moratín, compuesta, con toda probabilidad, poco tiempo después de la muerte de su padre, escribe: "Flumisbo en la memoria/ durará de los hombres,/ sin que fugaz el tiempo/ su duración estorbe" (1830-1831, IV, pp.187-189).

La afinidad espiritual del hijo con el padre se deduce de las lacónicas y desconcertantes frases, tan citadas: "Obiit Pater; ego triste", "sepeliverunt", con que Leandro empieza a redactar $(11,12$.V.1780) sus notas diarias, a las que pondrá el título de Apuntes of mi Father and mines (Andioc 1968). Estos apuntes pueden interpretarse como la demostración de su decisión por continuar la tarea poética emprendida por don Nicolás. Es significativo que decidiera imitar en estas notas el método utilizado por su padre y que incluso usara el mismo cuaderno en que éste había redactado cotidianamente sus apuntes hasta una semana antes de su muerte (4.V.1780).

La idea de publicar una edición de la obra de don Nicolás era un antiguo proyecto suyo, nacido probablemente a raíz de la muerte de su padre. Sempere y Guarinos en el artículo que dedica a don Nicolás en el Ensayo de una biblioteca española de los mejores escritores del reynado de Carlos III (Sempere y Guarinos, 1785-1786, I, pág. 63), siete años después de su muerte, alude a este proyecto:

D. Leandro Fernández de Moratín, hijo del autor de este Canto [Las Naves de Cortés], había pensado en escoger las mejores poesías impresas de su difunto padre, y añadiendo algunas otras manuscritas, exercitarse en este ûtil trabajo de analyzarlas. En la presente ha manifestado, que es muy capaz de desempeñar esta empresa, que aunque parece fácil, es de las más difíciles, y que piden la mayor inteligencia y gusto.

El proyecto no pudo realizarse hasta 1821 . Entre los motivos del retraso podemos imaginar una serie de problemas económicos y técnicos que plantearía a Leandro preparar un libro de poesía de Flumisbo Thermodonciaco. No debía serle fácil el tener que compaginar esta tarea de editor con su trabajo en un obrador de joyería (1780-1786).

El preparar una edición de las poesías del padre era un proyecto importante para él no sólo por su padre mismo sino porque le brindaba la oportunidad de espigar entre la entera producción poética de don Nicolás aquellas poesías que observaban mejor la estética neoclásica después de someterlas a retoques y correcciones que en su opinión necesitaban para librarlas de las reminiscencias barrocas tan congeniales al padre, y que tan poco se compaginaban con su concepción estética. Así sus futuros lectores podrían constatar que gracias a 
que don Nicolás "se atrevió a sostener nuevos principios, y a combatir errores, nacidos del mal gusto que generalmente se extendía a todos los ramos de la literatura" la poesía castellana superó el "último grado de corrupción" que imperaba en España (1821, pág. LIII).

Son muchos los años que transcurren desde que fue concebido el plan, al que alude Sempere y Guarinos, hasta 1817 , fecha en la que prepara la edición de las OP, tal y como informa a J.A. Melón desde Montpellier, en la misma carta que acabamos de citar: "Muy presto estará en estado de imprimirse la colección de obras pósthumas de mi Padre" (Andioc, 1973, pág. 380).

Inarco divide las OP en tres partes, la "Vida del Autor" (pp. I-LIV), la "Colección de poesías" (pp. 1-174), que merecen más bién el nombre de antología, y una serie de "Fragmentos" entresacados de algunas de las obras (pp. 175-224). Acompaña además a la edición una nota dirigida "Al Lector" ( 2 pp.).

La "Vida del Autor" le brinda la oportunidad de plasmar en un texto todas las ideas y reflexiones que venía proyectando, ya desde su juventud sobre la figura y obra paterna. Aquí traza un perfil paterno de perfecto "hombre de bien" y ejemplar padre de familia ${ }^{5}$ con el objetivo de ofrecer a la posteridad una imagen modélica de don Nicolás que sirviera para ensalzar aún más su labor creadora. No es extraño pues, que describa el panorama literario español en el que emerge la figura de don Nicolás en términos más desoladores de lo que en realidad parecía, atribuyéndole, para usar las palabras de J. M. Caso (Caso, 1980, pp. 5-18) "un valor y un peso específico superiores a los que realmente tuvo entre 1759 y 1764 ".

A pesar de no ser verídicos algunos episodios de la biografía de don Nicolás, es lógico que Leandro haya tenido un especial interés en difundirlos entre sus lectores. Este hecho, más que a la falta de perspectiva o fallos de la memoria de Inarco, nos parece atribuible a la intención perseguida por éste. De esta manera pueden justificarse las exageraciones e inexactitudes que varios críticos han señalado (Cotarelo, 1897, pp. 47-48, 84, 94-96; Simón Díaz, 1944, pp. 154-177). Durante años, tal y como era el deseo de don Leandro, estos datos se han utilizado repitiendo lo que él quería que se dijese, sin sopesar que precisamente esto constituía su intención. Leandro considera importante este capítulo porque piensa que lo que aquí se dice puede ser útil para la historia de la cultura "por la conexión que tienen con los sucesos públicos de su tiempo, y las memorias que recuerdan del estado y progresos de nuestra literatura, durante la mayor parte del reynado de Carlos III" (1821, "Al Lector").

Buen testimonio del fin perseguido es la nota que acompaña a la oda que dedicó A la memoria de su padre, que citamos:

5. Precisa Leandro (OP, pág. XXII) "Las atenciones de su casa, el amor a su esposa, la educación de un hijo (en quien ya descubría prendas, no desconformes a la celebridad del apellido que había de heredarle)". 
Las noticias críticas e históricas de su vida, publicadas pocos años hace al frente de sus Obras póstumas, dan a conocer cuan benemérito fue este poeta, de la celebridad que adquirió en su tiempo, y aún conserva en el aprecio de los inteligentes" (1830-1831, IV, pág. 338).

En la nota "Al Lector" Moratín hijo justifica ante sus destinatarios sus criterios de selección, que son diferentes para cada una de las dos partes. En la selección de las poesías subraya que se limita a cumplir "religiosamente la voluntad del autor", y las edita con las correcciones que existen en un manuscrito firmado, que entregó el escritor, don Nicolás, pocos meses antes de morir, a su íntimo amigo italiano Ignazio Bernascone. De este modo cree dejar muy claro que él no ha cooperado en la obra del padre y que su cometido ha sido únicamente el de un editor escrupuloso.

Por el contrario, en los "Fragmentos" seleccionados, no le cabe más remedio que confesar su propia intervención: "La única libertad que ha parecido disculpable, ha sido, la de incluir algunos fragmentos muy escogidos del poema didáctico intitulado La Diana, y de las tragedias Lucrecia, Hormesinda y Guzmán; suprimiendo en ellos uno u otro verso, cuya conservación no era del todo necesaria" ("Al Lector").

Estos dos criterios que Leandro declara haber seguido al editar las OP, y que después comentaremos, están estrechamente ligados con los juicios que formula sobre la producción creativa paterna. Resulta evidente, en las OP y en el "Prólogo" a sus comedias (Fernández de Moratín, Leandro, 1825), que concede mayor importancia a la producción lírica de don Nicolás que a la teatral. Demuestra conocer con profundidad los defectos de que adolecían las piezas teatrales del padre: "carencia de fuerza cómica, de propiedad y de corrección en el estilo" sin olvidarse de nombrar la abundancia de "episodios inútiles que entorpecían las fábulas" (1830-1831,II, pp. XXXIII-IV). No obstante le ponga como ejemplo de no haber sabido aplicar los nuevos preceptos neoclásicos en la escena española dotándola "de una regularidad, que se consideraba impracticable" (1821, pág. LIV).

A pesar de no poder formular juicios elogiosos sobre él, ya porque su estética neoclásica se lo impidiera, ya porque él sabía muy bien que no habría logrado nada positivo ensalzándola, no deja de anotar:

Lo menos apto de su talento para la imitación dramática, dio a luz una comedia y dos tragedias, que aunque muy superiores a todo lo que entonces se admiraba en nuestra escena, no llegan todavía a aquella difícil perfección que se exige en esta clase de composiciones (1830-1831, IV, pág. 338).

Al igual que Pietro Napoli Signorelli (Napoli Signorelli, 1790 VI, pp. 8-11) considera que de la producción teatral de su padre es la Hormesinda la "más laudable por algunas situaciones interesantes, por las buenas imitaciones de Virgilio, por su lenguage y versificación, que por el artificio de su fábula" (1830-1831, II, pág. XXXVI). 
En la lírica, en cambio, le sitúa a la altura de los "buenos poetas antiguos españoles" y no duda en considerarle un imitador de Petrarca en la poesía amorosa, opinión confirmada en las OP al elegir como primer texto un soneto dedicado a "Dorisa".

¿Es posible creer a Inarco Celenio y pensar que existe o ha existido efectivamente este manuscrito de las poesías? ¿Hemos de considerar su explícita participación de poda y concentración en los "Fragmentos" como una mera disculpa para justificarse ante sus lectores por todas las correcciones a las que había sometido la total producción poética de Flumisbo Termodonciaco?

Entre la numerosa correspondencia que cruza con sus amigos hay dos cartas en donde aparecen unos párrafos que pueden servir de contrapunto a lo que cuenta en la nota "Al Lector" y en la "Vida del Autor". Una de ellas, la dirigida a Dionisio Solís, está escrita en París el 2 de Noviembre de 1818; la otra se la envía a Juan Antonio Melón desde Burdeos el 28 de Octubre de 1821.

A Dionisio Solís, Moratín, le informa confidencialmente sobre cuál ha sido su cometido de editor tanto de las obras paternas como de las suyas propias. Cuenta, pues, a Solís:

En el imbierno anterior [1817] arreglé y puse en términos de poderse imprimir las obras líricas de mi padre, tan escogidas y castigadas que, pudiendo haber formado tres o quatro tomos con ellas, no pasarán de uno. En éste (se entiende: imbierno) creo que quedarán corrientes mis comedias, corregidas como Dios me ha dado a entender, y precedidas de una noticia histórica de nuestro teatro durante el siglo XVIII (Andioc, 1973, pág. 399).

Como acabamos de constatar aquí, Inarco no solo avala la inexistencia del autógrafo, sino que además nos informa sobre cúal ha sido su trabajo como editor de las obras paternas al equipararla a su tarea de editor de sus propias obras. Si entresacamos los verbos de esta cita encontramos la clave de cuál fue su cometido principal como editor paterno: arreglar, escoger y castigar, tuviera o no presente el autógrafo de don Nicolás, fue la labor de Leandro. Tarea que, como bien sabemos, es la característica de nuestro poeta y esencial en sus propias obras. Sirvan de ejemplo las correcciones a que sometió la Lección poética, aparecida en la edición de París de 1825 con 249 versos menos como ya notó Cotarelo (Cotarelo, 1897, pp. 94-96 y Rodríguez Sánchez de León, 1986).

Este concepto suyo de suprimir todo lo que no es estrictamente necesario vuelve a ser mencionado en la carta que escribe a Melón nada más publicarse las OP:

Ahora [1821] me ocupo en arreglar y cepillar las mías, y de el rebusco que he hecho resulta que, omitiendo algunas, se compondrá con las que dejo un tomillo igual a las de mi padre (Andioc, 1973, pág. 464).

Declaraciones tan confidenciales de Inarco a dos amigos lejanos son un cabo suelto que nos sugiere el papel que el hijo jugó en la obra póstuma paterna. Un lector atento al cotejar la producción lírica que don Nicolás publicó 
en vida con la aparecida en las OP, como sucedió a Foulché-Delbosc (1892) se encuentra ante el dilema de si corresponden a versiones distintas de una misma poesía o a poesías diferentes. Es precisamente en este cotejo donde mejor se puede calibrar la magnitud de su tarea de corrector.

De entre las poesías que ha escogido de El Poeta (Fernández de Moratín, Nicolás, 1764) para las $O P$ en la única que no ha intervenido ha sido en el epigrama Filena Devota.

Examinemos por ejemplo, aunque sumariamente, por falta de espacio, la silva escrita en honor de la boda de la Infanta María Luisa, hija mayor de Carlos III, con el Archiduque Leopoldo de Toscana publicada en El Poeta (pp. 113-128) y seleccionada en las OP (pp. 11-16).

La estructura de una forma poética como la silva le permite reducir los 325 versos que tenía en el Poeta a 136 en las OP. Ha suprimido nada menos que 235vv: 8, 9, 14-19, 27, 34-35, 38-80, 83, 84, 89-109, 120, 121, 126-131, 135, $142-144,152-155,162,165,178-199,201-211,215-219,221-223,226-276$, 280-305, $311-324$.

Todos estos versos corresponden a detalles que desvirtúan la trama del poema, como por ejemplo:

Oh! venturoso día!/ en el qual ensalzados/ con nudos reiterados/ los Austrias, y Borbones, / las Aguilas, las Lyses, y Leones/ más hermanarse veo (vV. 89-94)

y los versos finales del poema:

Cerradlas, que no es bien que estén abiertas./ Y, o jóvenes, y vírgenes hermosas,/ ya vuestras suertes llegarán dichosas,/ no Amor todo lo ha dado:/ Callad, callad, bastante hemos cantado./ Con dulces voluntades/ vivid eternidades,/O! consortes dichosos (vv. 311-318).

Ha conservado intactos $55 \mathrm{vv}$. que le sirven para mantener la estructura del poema:

$1-7 \leftrightarrow-7,8-10 \leftrightarrow 0-12,12-18 \leftarrow 20-26,19-24 \leftarrow 28-33,28 \leftarrow 36,32 \leftarrow 82$, $34 \leftrightarrow 86, \quad 37-39 \leftrightarrow 10-112,41 \leftrightarrow 14, \quad 44 \leftrightarrow 17, \quad 47 \leftrightarrow 22, \quad 49 \leftrightarrow 24, \quad 50 \leftarrow 125$, $51 \leftrightarrow 32, \quad 56 \leftrightarrow 34, \quad 57 \leftrightarrow 36, \quad 59 \leftrightarrow 38, \quad 60 \leftrightarrow 39, \quad 62 \leftrightarrow 41, \quad 65 \leftrightarrow 47$, $67-69 \leftrightarrow 49-151, \quad 74 \leftrightarrow 158, \quad 88 \leftrightarrow 770, \quad 102 \leftrightarrow 213, \quad 120 \leftrightarrow 278, \quad 121 \leftrightarrow 279$, $130-134 \leftrightarrow 306-310$.

Los 7 primeros vv:

Ven, Hymeneo casto,/ hijo de Urania bello,/ que al tálamo las vírgenes conduces./ Ven con ligero paso,/ suelto el rubio cabello,/ con la antorcha nupcial, que arroja luces:/ y quando el ayre cruces (vv. 1-7),

y los vv. que le sirven para terminar el poema, al haber suprimido del 311 al 324:

Mas ya el Héspero viene:/ corre estrella veloz, ¿qué te detiene?/ Bajad los pabellones,/ Oh! Cupido!, y echad los aldabones/ a las doradas puertas $(130-134 \leftrightarrow 306-310)$. 
Ha vuelto a escribir completamente $36 \mathrm{vv}$, procurando imitar lo más posible a su padre:

$25-27,30,53-55,70,71,77,78,81,87,94,99,100,104-106,108,109$, $112-118,122-129,135$

que arbolando algún día,/ en fiera lid dudosa,/ los temidos pendones/ con águilas augustas y leones,/ dará más timbres a su estirpe clara./ Austria y Castilla le serán deudoras/ de los triunfos que Marte le prepara,/ si acaudilla sus huestes vencedores (vv. 122-129),

y ha retocado $45 \mathrm{vv}$ :

$$
\begin{aligned}
& 13 \rightarrow 11,36 \rightarrow 29,81 \rightarrow 31,8 \rightarrow 33,113 \rightarrow 40,115-116 \rightarrow 42-43, \\
& 118-119 \rightarrow 45-46,123 \rightarrow 48,133 \rightarrow 52,137 \rightarrow 58,140 \rightarrow 61,145-146 \rightarrow 63-64, \\
& 148 \rightarrow 66,156-64 \rightarrow 72-80,166-169 \rightarrow 82-86,171-174 \rightarrow 89-93,175 \\
& 177 \rightarrow 96 \quad y 97,200 \rightarrow 98,212 \rightarrow 101,214 \rightarrow 103,220 \rightarrow 107,224 \rightarrow 110,225 \rightarrow 111, \\
& 27 \rightarrow \rightarrow 119,325 \rightarrow 136 .
\end{aligned}
$$

Estos retoques son de diferente envergadura:

11:"La esplendorosa tea" $\nless$ 3: "de esto la nupcial tea"; 63-64: "No así las de mi patrio Manzanares,/ que en otro tiempo ufano" $\leftrightarrow 45-146$ : "Ias ninfas de mi patrio Manzanares,/ Manzanares que ufano"; 29: "deidad en dulce ardor has inflamado" 37 : "Deydad al dulce yugo has anudado"; 85-86: "ni las vírgenes bellas,/ ni los mancebos que la amaron antes" 469 : "Ni niños, ni muchachas la apetecen"; 136: "el instante feliz. Ven Hymeneo 335 : Ven, Hymeneo, ven: ven, Hymeneo".

En la oda El premio del canto (OP, pp. 64-65) que en el Poeta (pp. 26-27), aparece con el título $A$ Dorisa, a pesar de que se respete el número de versos 24 , se observan los siguientes cambios:

Conserva invariables $6 \mathrm{vv}: 1,2,6,7,13 \leftrightarrow 7,14 \leftrightarrow 18$, ya que el 23 y el 24 son iguales al 1 y 2 "Dame la limetilla/ con el Pedro Jiménez,"; 6-7: "En sus convites beben,/ y en copa de oro a Jove"; 13-14: "Este licor el numen/ para cantar enciende".

Retoca 4vv: 3-5, 8: 3-4: "Dorisa, si me pides/ que tus años celebre" $\leftrightarrow-4$ : "Dorisa, si procuras/ el que yo te celebre" se repiten retocados también aquí en el 21 y 22; 5: "De este néctar los Dioses 5 : "De este vino los Dioses"; 8: "le sirve Ganimedes" $\leftrightarrow$ : "le sirve de Ganimedes".

Ha vuelto a escribir 10 vv.: 9-12, 15-20, que corresponden a la parte central del poema: 9-12: "Este licor suave/ da furores alegres,/ disipando del alma/ inquietudes crueles" $\leftrightarrow-12$ : "con él brinda Mavorte/ a Venus la del Erix,/ y el Padre Baco brinda/ por la Eleusina Ceres"; 15-20: “y así, mientras de rosa/ me corono las sienes, / y añado cuerdas de oro/ a la lira luciente,/ para que el plectro dócil/ son delicado preste" $45-16,19-20$ : “¿Aquel viejo de Teya,/ joven de Tebas éste. /.../ por lo qual entre tanto,/ que la cytara temple". 
Por el contrario en el epigrama Reflexión moral (OP, pág. 130) compuesto por cuatro versos su intervención ha consistido en retocar dos versos: 2: "miraba el Doctor Pandolfo" 2 : "Contemplando estaba Poncho"; 4: " Valgame Dios! lo que somos" 4 : "Oh mortales! lo que somos!".

Los títulos, al igual que los poemas, también ha sufrido modificaciones, desaparecen los números romanos que indicaban el número de orden de las composiciones, que en un principio había incluido en el ms (v.i.II), clasifica los poemas y elimina todo lo que no es estrictamente necesario: Epigrama. Reflexión moral «Epigrama II; Oda. El premio del canto $\leftrightarrow$ A Dorisa. Anacreóntica III; Epigrama. Filena Devota $\leftarrow$ Epigrama IV; Oda. El Arroyo $\leftrightarrow$ De un arroyo. Anacreóntica VIII; Oda. Traducción de Horacio $\Theta d a I V$ de saphicos y Adónicos. Traducción de Horacio (Lib. 1, Od. 22) con la propia medida; A las bodas de la Infanta de España Doña María Luisa de Borbón con el Archiduque de Austria Pedro Leopoldo WII Epitalamio. A las bodas de la serenísima señora Doña María Luisa, Infanta de España, con el Señor Archiduque Leopoldo. Sylva II; Oda. Los dos niños $\leftrightarrow$ Silva Num. IX. Monostrophe. Anacreóntica XIX.

¿Pudo don Nicolás ser capaz realizar estas correcciones? Si examinamos el poema que dedicó A las niñas premiadas por la sociedad económica de Madrid en la distribución de premios de $1779^{6}$, escrito pocos meses antes de su muerte y, que al no ser seleccionada en las $O P$, no ha sufrido ningún retoque, constatamos que es un texto que confirma, según puntualizó Lázaro Carreter (Lázaro Carreter, 1953, pp. 35-36), la imposibilidad de que don Nicolás hubiera podido acuñar este poema en la misma época en que corregía y preparaba las poesías aparecidas en las OP. Posee todas las caracteristícas poéticas de nuestro autor que han desaparecido en las $O P$, y puede ayudar mejor a comprender como Leandro ha actuado para dejar sólo lo esencial.

Retomemos las declaraciones que Leandro hace en la nota "Al Lector" y en la "Vida del Autor", ideadas, como ya dijimos, para convencer a sus lectores de su no modificación de la obra paterna.

Las contradicciones que aquí se aprecian sirven de aval a la censura de los textos. No es casual que en las OP don Leandro se haya inventado la historia de la existencia del manuscrito de las obras líricas del padre. Es aquí precisamente en donde don Nicolás podría tener mayor fortuna y él más libertad para llevar a cabo sus correcciones. En la producción poética su tarea de corrector queda más disimulada debido a la propia configuración del ejercicio literario y le permite justificar a Inarco, además, la existencia de un manuscrito que avale la producción lírica del padre; en las obras dramáticas su labor de corrección era casi imposible, ya que significaba cambiar el texto y la forma casi integramente. Ante la producción teatral no le cabe más remedio que optar por publicar solamente unos "Fragmentos". Tal es, por ejemplo, el sentido que tienen sus

6. [“_Habéis ya, padres de la patria dado?”] Aparecido en Noticias de los premios distribuidos a las discípulas de las quatro escuelas patrióticas de Madrid, Joachín Ibarra, 1779, pp. 3-19. Reproducido en BAE, pp. 27-31. 
palabras sobre la tragedia Guzmán el Bueno. La alaba, al igual que Napoli Signorelli (Napoli Signorelli, 1790, VI, pp. 8-11), por los efectos heroicos y por su costumbrismo (1830-1831, II, pág. XXXVI) pero sabe bien que es irrepresentable:

Nunca se ha representado aunque en su lectura hallan los inteligentes muchas qualidades dignas del mayor elogio. Más de una vez han solicitado los cómicos que pusiera la mano en ella el autor de El sí de las niñas, y siempre se ha negado a hacerlo (1821, pág. XLIII).

En un asunto de tanta trascendencia como es el de establecer quien es el depositario del autógrafo, Inarco parece contradecir lo que dice en la nota "Al Lector" con lo que escribe en la "Vida del Autor". Aquí no especifica que el depositario del manuscrito sea o haya sido Bernascone, al no mencionar el nombre de Bernascone, se deduce que es él, Leandro, quien custodia el autógrafo. "Hay que atribuir a la fortuna", escribe Moratín hijo, "el que en medio de tantas controversias y perquisiciones judiciales, se haya logrado conservar la colección de sus obras poéticas, como hoy se publica, y en los términos en que él la tenía arreglada y dispuesta ya para la prensa" (1821, pág. XLVIII).

Añadamos que el confesar que el depositario del manuscrito era Bernascone, y no su único hijo, Leandro, que a la sazón tenía veinte años y era ya un poeta conocido $^{7}$, es también una declaración que sirve para glorificar la obra de Nicolás Moratín. Bernascone de entre los amigos de don Nicolás que se reunían en la tertulia de la Fonda de San Sebastián, no era conocido como poeta como testimonia la Silva A don Ignacio Bernascone, excelente en la esgrima (1821, pp. 169-172) y por lo tanto la posteridad no le podría achacar que hubiera sido el "Aristarco" que le habría corregido las poesías (Quintana, 1867, pág. 148).

Quizás también por no ser poeta y no estar sujeto a represalias literarias Bernascone firmaría el prólogo de la Hormesinda, que más que un prólogo era una respuesta a las duras críticas que Joaquín José de Flores había hecho a la Lucrecia (Flores y la Barrera, 1763). Es significativo que en la Hormesinda aparezcan versos de J. de Iriarte, C. Ortega y G.B. Conti y que el prólogo lo firme el único que de entre ellos no es poeta ${ }^{8}$.

Es evidente que Leandro para respaldar su inocencia necesitaba precisar que una persona ajena a él es quien custodiaba el autógrafo. No hay que olvidar que no habían pasado tantos años desde que J.M. Vaca de Guzmán, el vencedor del premio de la Academia (Vaca de Guzmán, 1778), publicó las Advertencias a las naves de Cortés destruidas (Vaca de Guzmán, 1787), en donde ponía de manifiesto las numerosas correcciones que había sufrido la edición póstuma respecto al poema presentado al concurso de la Academia. Tales Advertencias,

7. Había ganado el accésit en el concurso de la Real Academia Española de La toma de Granada por los Reyes Católicos D. Fernando y $D^{a} I$ Isabel. Romance endecasílabo impreso por la Real Academia Española por ser entre todos los presentados el que más se acerca al que ganó el premio. Su autor, $D$. Efrén de Lardnaz y Morante, Madrid, Joachín Ibarra, 1779.

8. J.M. de Flores y La Barrera, 1763. II, pp. 99, 128; Cfr. E. Cotarelo. 1897, pp. 84-85 y M. Menéndez y Pelayo. 1940. III, pág. 294, n. 
sin lugar a dudas, son un texto que confirma la ayuda que Moratín hijo prestó a su padre y se constata además cómo, al publicar este poema en las OP, utilizó Las Advertancias para corregir aún más, sobre la de las enmiendas que había evidenciado Vaca de Guzmán (Dowling, 1977, pág. 449).

Con la voluntad de ratificar al lector que él, Leandro, no había participado en las correcciones de las poesías paternas cuenta también en la "Vida del Autor" el motivo que movió a su padre a preparar una edición corregida de sus poesías que merece la pena reproducir íntegramente:

En vista del poco aprecio que había merecido su ensayo épico [Las naves de Cortés], no quiso Moratín aspirar de nuevo a los premios que la misma Academia propuso después; y pensó en ocupar las horas que le quedaban libres en elegir de sus obras impresas y manuscritas las que mereciesen corrección, limarlas con esmero, formar una colección de ellas y publicarlas (1821, XLVIII).

Es obvio que no tenemos elementos suficientes para aceptar o rechazar como verdadero este proyecto que cuenta Inarco, pero nos parece revelador, para calibrar aún más la importancia que tendría para los Moratín, el que las Naves de Cortés no obtuviera ni siquiera un accésit en la Real Academia. Por otra parte, para Moratín hijo, este canto, tan retocado por él, constituye un hito de perfección en la historia del género: "Se considera -escribe- como lo más perfecto que tenemos en este género" (1830-1831, IV, pág. 338).

Creemos que quizá este fracaso académico contribuyó en modo determinante a que Inarco decidiera demostrar a sus contemporáneos que el poema de su padre era superior al vencedor, a la vez que le empujaría a llevar a cabo su proyecto de ensalzar el nombre paterno y defenderle en las contiendas literarias de la época, a las que significativamente P. Napoli Signorelli (Napoli Signorelli, 1790, VI, pág. 8) alude refïriéndose a don Ramón de la Cruz.

Cabe todavía preguntarnos: ¿Leandro era o no consciente de que al limar y transformar los textos paternos trasmitía a la posteridad una falsa imagen de la obra poética de su padre? La respuesta aparece en unas líneas entresacadas de la carta que envía a Melón desde Barcelona el 11 de julio de 1821: "he cumplido una deuda de agradecimiento y amor a mi padre, y todo lo demás me importa muy poco" (Andioc, 1973, pág. 444).

Aquí, además de confirmar su objetivo, es como si quisiera pedir disculpas a la Literatura por las libertades que se había tomado al manipular los tex tos del padre; más que la ética profesional puede su gratitud filial, cantada en la Elegía a las Musas: "Si pude un día,/ no indigno sucesor de nombre ilustre,/ dilatarle famoso, a vos fue dado/ llevar al fin mi atrevimiento" (1830-1831, IV, pp. 327-328, vv.15-18).

Bien sabría Inarco que era imposible alcanzar la tan deseada "fama póstuma" del padre si antes no creaba las premisas en las OP para que la poesía de don Nicolás se afirmara como la auténtica neoclásica ya que él "nunca 
aspiró a la gloria de poeta lírico", y las poesías que escribió fueron para "desahogo de su imaginación y sus afectos, o para corresponder agradecido a los que estimaban en algo las producciones de su pluma" (1830-1831, II, pp. LXIII-IV).

Pretende que aquí quede patente que gracias al poeta Nicolás Moratín, la poesía castellana a la que había "encontrado grosera y tribial en manos de ignorantísimos autores, se la dejó elegante, florida, patética, docta y armoniosa a los que siguieron después" (1821, pág. LIV).

Las OP, fruto de años de meditación y trabajo de Leandro, son el resultado de la colaboración padre-hijo; fueron dirigidas a que el apellido Moratín perdurase en el tiempo como figura clave de la reforma literaria española y a homenajear al padre, como demuestra al seleccionar los poemas dedicados a sus verdaderos amigos y benefactores. El hijo ha preferido dejar a la posteridad una obra paterna reducida, pero concentrada, donde no aparezca más que lo estrictamente necesario con el mero fin de librarla de todo lo que él criticaba: "paranomasias y equivocos, laberintos, ecos, retruecanos y quanto desacierto es imaginable" (1821, pág. IV).

Para poder calibrar el peso que tuvo la figura de don Nicolás entre sus contemporáneos hay que leer sus textos primitivos. Se puede aplicar a los textos de su padre aparecidos en las OP, los juicios que Leandro formula sobre su producción lírica en el prólogo de sus comedias:

Se reconocen las máximas que seguía el autor, según la diferencia de los géneros, de los argumentos, de la versificación y del estilo en que las escribía; los originales que procuraba imitar, y su cuidado nunca desmentido de sujetar los ímpetus de su fantasía a las leyes del raciocinio y del buen gusto (1830-1831, II, pág. LXI).

Por el momento no contamos con documentos que avalen la inexistencia del autógrafo de las poesías de don Nicolás. Una cosa es cierta; si Moratín hijo se hubiera limitado a transcribir el manuscrito autógrafo de don Nicolás que éste entregó a Bernascone, habría aparecido a la muerte de don Leandro en el detallado inventario de sus papeles que redactó Manuel Silvela (Sánchez Mariana, 1986, pp. 205-223), al igual por ejemplo, que el Diario y los certificados familiares; este hecho no ocurre, y por tanto constituye una prueba más de la inexistencia del autógrafo de don Nicolás. ¿Habrá existido alguna vez? Pudiera muy bien ser que sí y que don Leandro lo destruyera después de publicadas las OP para que la posteridad no supiese nunca las correcciones a que él había sometido la producción textual paterna.

\section{Estudio del manuscrito}

El autógrafo de las OP según el registro general de la BBMM lleva el número 6734 y el 474 de la sección de manuscritos y figura en ella con la 
signatura 25/3/10. Llegó aquî ${ }^{9}$ alrededor de 1965 junto con los papeles de Claudio Rodríguez Porrero ${ }^{10}$. Los únicos datos que poseemos nos los suministra una carta autógrafa, sin fecha, de Emilio Cotarelo a Rodríguez Porrero, que acompaña el autógrafo. Se adquirió en Barcelona a un heredero de la viuda de Roca. En esta carta Cotarelo atribuye el manuscrito a Leandro Fernández de Moratín y es de la opinión de que las OP están "demasiado limadas por su hijo".

De entre los escritos contenidos en el manuscrito son los "Fragmentos" los que atraen la atención de Cotarelo, porque "las correcciones son en gran parte inéditas; y en este concepto tienen esos fragmentos más valor del que pensábamos, puesto que son obras no conocidas de Moratín el hijo".

Este juicio, desconocido durante todos estos años, es una prueba más que atribuye la paternidad de las correcciones de las poesías de don Nicolás a Leandro. Confirma además las sospechas que Cotarelo deja entreveer en su libro Iriarte y su época (1897).

\section{Descripción del manuscrito}

BBMM, ms 25/3/10

Leandro Fernández de Moratín

S. XVIII-XIX [1817-1821]

Título: Obras póstumas de don Nicolás Fernández de Moratín

Papel de hilo, 93 fols., incompleto.

(255 X $195 \mathrm{~mm}$.).

El manuscrito está dividido en tres partes" ${ }^{\prime}$. Cada una de éstas posee una portada independiente, insertada posteriormente. La numeración moderna a lápiz en el ángulo superior derecho de los rectos, del fol. 1 al 93, no se corresponde con la secuencia original de escritura de Leandro Moratín, por haberse alterado la colocación de algunos folios. Ateniéndonos al orden original de escritura hemos numerado nuevamente los fols. del ms. en el ángulo inferior izquierdo de los rectos asignándoles los números siguientes: 1-23«22-44; $24-35 \leftrightarrow 82-93 ; 36-72 \leftrightarrow 45-81 ; 73 \leftrightarrow ; 74-83 \leftrightarrow 42-21 ; 84-93 \leftrightarrow 2-11$.

Esta alteración en la numeración atañe a las tres partes que forman el ms. Así, en nuestro trabajo, la que consideramos como $1^{\mathrm{a}}$ parte era la antigua $2^{\mathrm{a}}$, la $2^{\text {a }}$ era la $3^{\text {a }}$ y la $3^{\text {a }}$ era la primera.

9. Queremos dar las gracias públicamente a María Dolores Vives por las facilidades que nos ha dado para trabajar en la Biblioteca.

10. Hemos consultado sin ningún éxito el Catálogo de las cartas y demás documentos autógrafos que componen la colección de Claudio Rodríguez Porrero, BBMM, fols. 1-3; Comentarios y referencias publicadas en libros, revistas y periódicos sobre la colección de autógrafos de don Claudio Rodríguez Porrero, BBMM, 27/7/1; y el artículo de Mariano Rodríguez de Rivas.

11. Conservamos las grafías moratinianas pero modernizamos la acentuación y puntuación. 
De la segunda parte, que forma el corpus de las poesías, faltan en el ms. las siguientes composiciones que comprenderían las OP (pp. 88-144): Quintillas de la Fiesta de toros en Madrid [vv: 239-359 sin moverse de un lugar /.../ hasta que gane a Madrid], OP, pp. 88-93; Silva Al Capitán General D. Pedro Ceballos: por su gloriosa expedición a la Colonia del Sacramento [Musa, cantemos al varón glorioso], pp. 93-97; Oda Súplica despreciada [Erato, dulce Musa], pág. 97; Soneto Amor platónico [No fue la rica, inestimable trenza], pág. 98; Epigrama Saber sin estudiar [Admiróse un portugués], pp. 98-99; Canción $A P e-$ dro Romero, torero insigne [Cítara aurea de Apolo, a quien los Dioses], pp. 99-104; Soneto Atrevimiento amoroso [Amor, tu que me diste los osados], pp. 104-105; Oda En elogio de las niñas premiadas por la Sociedad económica de Madrid [No pido, sacro Apolo], pp. 105-111; Oda Amante feliz [Vencí, vencí, Cupido,], pp. 111-113; Romance Empresa de Micer Jaques Borgoñón. Dirigida al Duque de Medina Sydonia [En la Villa que Pisuerga], pp. 113-128; Oda Grato recuerdo [Noche postrera], pp. 128-130; Epigrama Reflexión moral [La calavera de un burro], pág. 130; Soneto Aplauso a Dorisa [Bendita sea la hora, el año, el día], pp. 130-131; Canto épico Las naves de Cortés [vv 1-408: Canto el valor del capitán hispano /.../ los reynos del ocaso y de la auroral, pp. 131-144.

Describimos el contenido del manuscrito según la nueva numeración propuesta:

Inc. (fol. 3r) “Obras póstumas de D. Nicolás Fernández de Moratín, entre los Arcades de Roma: Flumisbo Thermodonciaco..."

Expl. (fol. 93r) 5598. líneas

\section{PARTE I}

Compuesta por 21 fols., numerados del 1 al 21

Título (fol.1r): "Obras/ Póstumas/ de/ Don Nicolás Fernández de Moratín/ Vida del autor/ Escrito por su hijo Leandro/ Original/ Autógrafo".

Inc. (fol.3r): "Obras Póstumas..."

Expl. (fol.19v): "...produce la naturaleza no muchas veces".

Contiene: "Al Lector", ms., fols. 3r y v, OP., 2 pp.; "Vida del Autor", fols.4r-19v, pp. I-LIV.

En el fol. 2v. se lee la nota siguiente para la imprenta: "X Como en la pág". 1. la palabra Soneto, XX Cursiva como en la pág ${ }^{a}$, Dorisa ingrata, XXX Como la palabra Soneto, XXXX Redonda como la de los versos". Estas llamadas se refieren a los diferentes cuerpos de letras de los siguientes apartados: $\mathrm{X}=\mathrm{Al}$ Lector; $\mathrm{XX}=$ El editor; $\mathrm{XXX}=$ Vida del autor; $\mathrm{XXXX}=$ texto de Don Nicolás.

\section{PARTE II}

Compuesta por 51 fols., numerados del 22 al 72

Título (fol.22r): "Poesías/ de/ Don/Leandro [sic]/ Fernández/ de Moratín/ Originales/ Autógrafos" 
Inc. (fol.24r): "Soneto.Dorisa ingrata".

Expl. (fol.72v): "...se hacinaron los lauros".

Contiene: Soneto Dorisa Ingrata [Un alto y generoso pensamiento], ms., fol. 24r, OP, pág. 1; Oda Todas merecen [Agradanme las feas], fols. 24r y v, pp. 2-3; Romance Amor y honor [De la hermosa Belerifa], fols. 25r-26v, pp. 3-7; Oda El vino dulce [Venus y Baco un día], fols. 26v-27r, pp. 7-8; Epigrama Filena devota [De imposibles Santa Rita], fol. 27r, pág. 8; Soneto Libertad perdida [Qual gira el soto, de temor exento], fols. 27r y v, pp. 8-9; Oda Gocemos hoy [Hernando, si la vida], fols. 27v-28r, pp. 9-10; Sylva A las bodas de la Infanta de España, Da María Luisa de Borbón con el Archiduque de Austria Pedro Leopoldo [Ven Hymeneo casto,], fols. 28r-30r, pp. 11-16; Romance Don Sancho en Zamora [Por la ribera del Duero], fols. 30v-33r, pp. 17-23; Oda A los ojos de Dorisa [Ojos hermosos], fols. 33r-34r, pp. 23-26; Soneto Desengaño de amor [Verás, me dixo el flechador tirano], fol. 34v, pp. 26-27; Oda El arroyo [Vagaba por los montes], fols. 34v-35v, pp. 27-29; Oda Fuga inútil [Armaba Amor el arcol, fol. 35v, pág. 29; Silva Al Conde de Aranda, Capitán General y Presidente de Castilla [Quando mis versos a la edad futura,], fols. 36r-38r, pp. 30-34; Romance Abdelcadir y Galiana [Ya cabalga Abdelcadir], fols. 38r-42v, pp. 34-45; Soneto A D. Juan Bautista Conti, por su excelente traducción italiana de la primera Egloga de Garcilaso [Las bellas Ninfas del undoso río], fol. 42v, pp. 45-46; Oda Amor Aldeano [Hoy mi Dorisa], fol. 42v-43v, pp. 46-48; Epigrama Corrección oportuna [Anda, que con un indiano], fol. 43v, pág. 48; Canción Dorisa ausente [Enfin, Dorisa, enfin, que te partiste], fols. 43v-45r, pp. 49-52; Oda A los días del Coronel D. Josef Cadahalso [Hoy celebro los días], fols. 45r-46r, pp. 52-54; Soneto Modestia de Dorisa [Baja los ojos mi Dorisa hermosa], fol. 46r, pág. 54; Oda La vida poltrona [Ahora que he comido], fols. 46r y v, pp. 55-56; Oda El nido de Amor [El hijo de Venus], fols. 46v-47v, pp. 56-58; Silva Al Infante D. Gabriel de Borbón, durante la guerra de España con Marruecos [Celestes Musas de belleza eterna], fols. 47v-48v, pp. 58-60; Romance Consuelo de una ausencia [Ausentábase Alboraya], fols. 48v-50r, pp. 61-64; Oda El premio del canto [Dame la limetilla], fols. 50r y v, pp. 64-65; Oda La poesía inmortaliza a la hermosura [Dorisa, el dulce verso armonioso], fols. 50v-51r, pp. 65-66; Epigrama Laudable templanza [Ayer convidé a Torquato], fol. 51 r, pág. 67; Oda El sueño [Hay una gruta], fols. 51r-53r, pp. 67-71; Soneto Dorisa en trage magnifico [iQué lazos de oro desordena el viento], fol. 53r, pp. 71-72; Canción A D. Pedro Napoli Signorelli, autor de la Historia crítica de los teatros [De Febo las hermanas], fols. 53r-54r, pp. 72-74; Oda Todos son locos [Burla y desprecia el joven], fols. 54r y v, pág. 75; Oda $A l$ Duque de MedinaSydonia [Ay; no a la hercúlea enfermedad rendido], fols. 54v-55r, pp. 75-77; Soneto Amor constante [Dos veces vi la hermosa primavera], fol. 55v, pp. 77-78; Quintillas Fiesta de toros en Madrid [vv.1- 238: Madrid, castillo famoso /... y alrededor le ha observado], fols. $55 \mathrm{v}-59 \mathrm{v}$, pp. 78-88); Canto épico Las naves de Cortés [vv. 409-620: El Príncipe infernal, que conocía /... la cruz que tremolada va siguiendo], fol. 60r-64r, pp. 144-153; Oda Disculpas de un error [Niña, malhaya], fols. 64r y v, pp. 153-154; Oda 
Madrid antigua y moderna [Los sobervios palacios], fols. 64v-65r, pp. 154-155; Soneto A Dorisa mudable y hermosa [ $i$ Temes acaso que indignado ahora], fols. 65r y v, pág. 156; Oda Los dos niños [Era yo niño, quando], fols. 65v-66r, pp. 156-158; Epigrama La lengua patria [Preguntasme, ya lo veo], fol. 66r, pp. 158); Oda El sabio y el rico [Soy pobre; pero tengo], fol. 66v, pp. 158-159; Oda La muger humilde [Claudio, en toda la tierra], fol. 67r, pp. 159-160; Soneto Aviso a quien ama [iSon estos los sagrados juramentos], fols. $67 \mathrm{r}$ y v, pp. 160-161; Epigrama El gran teatro [El mundo comedia es], fol. 67v, pág. 161); Oda La barquerilla [En la olorosa], fols. 67v-70v, pp. 161-168; Oda Traducción de Horacio [El de la vida, Fusco, religiosa], fol. 70r-v, pp. 168-169; Silva $A D$. Ignacio Bernascone, excelente en la esgrima [Los que a su dulce acento], fols. 70v-72r, pp. 169-172; Soneto El escarmiento [Si fuere que después del fatal día], fol. 72r, pp. 172-173; Oda La fama póstuma [Musa, dame coronas], fol. 72r, y v, pp. 173-174.

En la parte superior izquierda del fol. $22 \mathrm{r}$, que sirve de portada, en una nota a lápiz de distinta caligrafía, se lee: "Nicolás F. Moratín. Publicadas en 1821 Barcelona".

En el fol. 23r de distinta caligrafía que el texto: "Autógrafs de Moratín/ cedits per l'impresor de ses obres En A. Roca de Bar[celo]na a En A. Saura".

Apostillas marginales: el Epigrama La lengua patria, fol. 66r, está escrito en el espacio libre del margen derecho que deja la oda Los dos niños, vv. 26-33. La oda a la Traducción de Horacio está escrita en el espacio libre del margen derecho que deja la oda La barquerilla, vv. 140-175.

A La derecha de la mayoría de los sonetos, epigramas, canciones y odas hay un número de orden tachado.

\section{PARTE III.}

Compuesta por 21 fols, numerados del 73 al 93

Título (fol. 73r): "Fragmentos/ de las obras de/ Don Nicolás Fernández/ de Moratín/La Hormesinda. Guzmán/ el Bueno. Lucrecia. La Dianal o Arte de la Caza./ Copia hecha por su hijo Leandro, conteniendo correcciones/ inéditas, también autógrafas, de/ éste último".

Inc. (fol. 74r): "3ํ Hormesinda Tragedia..."

Expl. (fol. 93r) "...injusto las soberbias gentes".

Contiene: Hormesinda. Tragedia: I.1, 6; II.5, 7; IV.1, fols. 74r-80v, pp. 194-211. Guzmán el Bueno: I.7; III.13, fols. $84 \mathrm{r}$ y v, 80v-21v, pp. 212-224; Lucrecia. Tragedia: I.4; II.7, fols. 84v-88r, pp. 185-194; Fragmentos. Arte de la Caza. Poema Didáctico: I; II; IV, fols. 88r-93r, pp. 175-185.

A la izquierda del incipit de cada uno de los apartados hay un número de gran tamaño, destinado al tipógrafo, que indica el lugar en donde tenían que colocarse estos fragmentos en las OP: "l" La Diana, fol. 88r, pág. 175; "20 Lucrecia." Tragedia", fol. 84v, pág. 185; "3 Hormesinda”, fol. 74r, pág. 194; 
"4" Guzmán el Bueno", fol. 80v, pág. 212. Fol. 93r: en el margen derecho del último renglón del tex to: "1047". Este número corresponde al número de líneas de este cuaderno. Hay también una suma: “4551+1047= 5598 líneas" que quizá correspondían al total de renglones del manuscrito.

En blanco los fols. 1v, 2r, 41 y $42 \mathrm{r}$ y v, 22v, 23v, 73v, 93v.

Están restaurados los fols. 2, 63 y 74 .

En un sello mojado se lee: "De la colección de autógrafos de Claudio Rodríguez Porrero", en el ángulo superior derecho de los fols. 1r, 2r, 3r, 4r, 22r, $23 r, 35 v, 36 r$ y en el inferior derecho del fol. 73r.

La encuadernación moderna, bastante mal ejecutada, es en tafilete marrón ( $205 \times 265 \mathrm{~mm}$.) con una rueda en seco en las pastas; las guardas son de baúl, en ellas está pegado el exlibris de Bartolomé March: "Non ego argento sed argentum bono et amicis meis". En el lomo, 4 nervios más modernos que la rueda, en letras doradas se lee: "FERNÁNDEZ/ MORATÍN/ ORIGINALES/ AUTÓGRAFOS".

\section{Diferencias del manuscrito para con las OP}

A pesar de que no haya dudas de que este manuscrito, conservado en la BBMM, fue el que utilizó la imprenta de la Viuda de Roca para componer la edición de las OP, se advierten algunas diferencias con la edición; aunque escasas, son significativas porque reflejan el proceso textual a que don Leandro solía someter sus propios textos y pueden ser un dato más para atribuirle la paternidad de las correcciones.

En primer lugar damos algunos ejemplos de las abreviaturas y las variantes ortográficas que aparecen en el ms., características de don Leandro como se puede comprobar en otros textos suyos como por ejemplo el Diario (Andioc, 1968), el Viage a Italia (Fernández de Moratín, Leandro, 1991) y las Apuntaciones sueltas de Inglaterra (Fernández de Moratín Leandro, 1867). Las correcciones abarcan tanto la parte que Leandro confiesa haber escrito: ("Vida del Autor") como las que declara que pertenecen al manuscrito de su padre que custodiaba Bernascone: el corpus de las poesías y el de los fragmentos.

Algunas de estas correciones no descartamos que las pudo realizar durante los casi cuatro años que se tardó en publicar las OP: las omisiones del autógrafo que aparecen en las OP y los añadidos en las OP que no aparecen en el ms. Las tachaduras probablemente fueron realizadas más por perfeccionismo que por economía de espacio.

Hemos preferido agrupar las diferencias de los textos según los tipos, porque a nuestro juicio, reflejan mejor el estilo moratiniano. Siempre que hemos logrado identificar los textos que aparecen tachados en el manuscrito los indicamos; éstos son también fiel reflejo de su manía de descartar todo aquello que no fuera estrictamente necesario. 
Abreviaturas del $m s$.

$\mathrm{q}^{\mathrm{Q}}=$ que; $\mathrm{s}=$ señor; $\mathrm{Sn} / \mathrm{S}=\mathrm{San} ;$ conocim = conocimiento; Hormsn $=$ Hormesinda; Mnza = Munuza; Guzmn = Guzmán; Tarq = Tarquinio.

Variantes ortográficas del ms. respecto a las $O P$

$\mathrm{i} \ll$ : ayrado, tyrano/a, ayre, heroyco, deleytosa, deydad; $c \ll z$ : vezes, estremeze, desgraziada, zefiros; v ↔: silvos, alvergan, Sebilla; v ↔ : Fabila; $g$ $\leftrightarrow$ : exerciese, exercito, dixe, exemplo, exercitaba, dixo, exercicio, exemplares, exercitaba, baxel; $\mathrm{j} \leftarrow$ : lexos, Xerez, dexarla, Roxas, dexa, dixo, dexó, fixar, baxando, Guadalaxara, embaxada, xayra, quexas, Borox, Xarifa, Ximena, Loxa, quixotes, floxas, reflexo, exemplo; -h- «emprehendiese; trahen.

Omisiones del ms. respecto a las $O P$

"Vida del Autor"

En la larga lista de nombres de literatos "en cuyas manos perecía la poesía castellana, sin doctrina, sin decoro, sin arte" omite a Juan Pedro Marujan, el traductor al castellano de Metastasio y Goldoni (ms. fol. 6v, OP, pp. X-XI).

En el romance Amor y honor ha omitido una estrofa entre la 9 y 10 :

Triste llega a los umbrales

de su dama y afligido,

sobre una encintada yegua

con el bozal de oro fino.

[Leonado era el bonete

y el alquizel berberisco,

y en la negra lanza cuelga

leonado pendoncillo].

Viola salir al balcón,

y con ademán sumiso,

arrodillando la alfana, inclinó el penacho altivo.

(ms. fol. 25v, OP, pp. 4-5, vv. 33-40).

En el romance $D$. Sancho en Zamora ha suprimido una estrofa entre la 12 y la 13:

Sus escuderos y dueñas

mesurados la acompañan:

ellas trahen ricas patenas,

ellos floxas martingalas.

[Contempla el pasado tiempo

quando en Burgos se críaba,

ve malogrado su amor, 
llora su ciudad sitiada]

Y quitando el antifaz,

la voz un poco levanta

y a su hermano le decía,

que se detiene a escucharla

(ms., fol. 31r y v, OP, pp. 18-19, vv. 45-52).

Oda El sueño

A guarecerme

de ardiente siesta

[que me molestas]

niño y cobarde

(ms. fol. 52r, OP, pp. 68-69, vv.32-37).

Lucrecia

¡De quantos pensamientos agitado

(Tarq.) mi espíritu vacila! [¿A qué he venido?

¿Qué he visto? ¿quién me angustia?] ¿Quién me ha

herido con rayo celestial?

(ms. fol. 84v, OP, pág. 185, I.4, vv. 1-3).

Ni a Colatino temo, ni a los suyos,

(Tarq.) [ni temo el ser escándalo a mi patria,]

ni me acobarda el riesgo, aunque evidente,

ni la muerte , ni el cielo...

(ms. fol. 85v, OP, pág.188, I.4, vv.49-51).

$\mathrm{Oh}$ ! quantos infortunios considero

(Espur.) que estan ya amenazando! Oh patria ![Oh patria]

Oh! antigua libertad!

(ms. fol. 85v, OP, pág. 188, I.4, vv.55-57).

\section{Hormesinda}

¡Será posible!

(Pelayo) [¡Mi hernana infiel, qué horror! ¿qué dices moro?]

(ms. fol. 77v, OP, pág. 204, II.5, v.34).

Guzmán el Bueno. Tragedia

Guzmán. Jimen. Araldo. Soldados. Acompañamiento

(ms. fol. 80v).

Guzmán. Jimen. Amir. Araldo. Guardias

(OP, pág.212, I.7). 
Añadidos en las $O P$ que no figuran en el $\mathrm{ms}$.

"Vida del Autor"

Sin embargo, el colector del Parnaso [D. Juan López de Sedano] se atrevió algún tiempo después a censurar en el tomo IX de su obra a D. Vicente de los Rios, y a Iriarte. Ni uno ni otro le perdonaron esta agresión, y el último publicó un difuso opúsculo, intitulado: Donde las dan las toman, en que se aprovechó de las citadas Reflexiones de Moratín y Ayala, para la amarga crítica que hizo de la colección de Sedano, y de sus opiniones literarias. La junta de San Sebastián vio con mucho sentimiento esta discordia; pero no la pudo calmar (1821, pp. XXVI-XXVII, ms., fol. 11v).

En esta ocasión escribió Iriarte unas curiosas observaciones, que leyó a la junta, sobre la varia construcción de las voces castellanas y su aptitud para las combinaciones armónicas; escrito muy apreciable, que reducido a menor extensión, le sirvió después para una de las notas con que ilustró su poema de la Música (OP, pp. XXX-XXXI, ms., fol. 13r).

\section{Guzmán el Bueno}

Guzmán, los que se precian de prudentes, (Amir) saben que esa fantasma que honor llaman es solo imaginaría, y que no existe sino en débiles almas (ms., fol.82r, OP, pág. 216, I.7, vv.77-80).

\section{Tachaduras en el ms. que no aparecen en las $O P$}

"Vida del Autor"

Tachados casi 9 renglones al hablar de los consejos y sugerencias que don Nicolás dio a Ignacio López de Ayala sobre la Numancia destruida:

Entre los pasages que le tachó, fue el de mayor importancia, una scena entera en que el poeta hacía salir al teatro a los jóvenes de Lucía, con los brazos cortados. Diole a entender Moratín lo repugnante, lo inútil y ridículo de este episodio y el autor agradeciendo el aviso, subscribió a su dictamen [...]. Incapaz Moratín de resolverse (OP, pág. XX, ms., fols. 30v-31r).

Tachados más de 2 renglones a propósito de la Antologia de la poesía castellana que publicó J.B. Conti:

A cuyo zelo deben agradecerse los bellísimos versos italianos en que se halla traducido lo mejor de Garcilaso, Padilla, Herrera, Figueroa, los dos Argensolas y otros insignes autores nuestros [...] Sólo llegaron a publicarse quatro tomos de esta colección (OP, pág. XXVIII, ms., fol. 12r).

Tachada una composición de 10 versos entre las odas El arroyo y La fuga inútil de la que logramos leer: v.3: Almanzor; v.5: Pica al Babieca; v.6: a Madrid; v.7: y a pesar de su?; v.8: llega; v.9: de la Puerta de la (ms., fol. 35v). 
Tachado un soneto entre las odas Los dos niños y El sabio y el rico del que hemos logrado leer:

\section{Promesas no cumplidas}

Me acuerdo que algún tiempo me decías:

primero dulce mía [...] que ya te olvide

el gran planeta que los cielos mide

volverá atrás a deshacer los días

y la informe? Diosa que las frías

nocturnas sombras cándidas preside?

huirá de Apolo cuyos rayos pide, antes que falten las promesas mías

$Y$ haciendo luego juramentos santos

la insignia a quien tu pecho exclamas?

besa tu hermoso [...]

Y añadirá a la voz perfido llanto

pues ni el sol aparezca, ni la luna

que Dorisa olvidó lo prometido

(ms., fol. 66r y v).

Silva al Conde de Aranda

En la dedicatoria el nombre del Conde, Don Pedro Pablo Abarca de Bolea, está tachado (OP, pág. 30, ms., fol. 36r).

\section{Oda al Duque de Medinasidonia}

En la dedicatoria el nombre del Duque, Don Pedro de Alcántara Pérez de Guzmán, está tachado (OP, pág. 75, ms., fol. 54v).

\section{Epigrama el gran teatro}

Tachada la segunda estrofa de las dos de que estaba formado (OP, pág. 161 , ms. fol. $67 \mathrm{v}$ ).

\section{Diana}

\section{Canto II Muerte de Fabila}

Tachada la primera estrofa que pertenece a:

Mas la tragedia más horrenda, y triste que España lamentó, fue de Favila:

¡Oh Monte Auseba, que el suceso viste!

Tú lo refiere, porque ya destila

mi vista fiel de lágrimas un río, viendo tal ruina en un monarca mío

(BAE, II, pág. 52b, ms. fols. 89v-90r, OP, pág. 179). 
Canto IV Alcázar de Segovia

Tachadas las dos primeras estrofas que no logramos leer (ms.fols. 90-91r).

Tachada una estrofa entre la 11 y 12 que hemos podido identificar como:

El humo, el agua, el fuego, la algazara,

los truenos y espantosos alaridos,

la rabia fulminante, el ansia avara,

los brulotes ardientes y sumergidos,

todo era asombro y confusión tan fiera,

como si el cielo abajo se viniera

(BAE II, pág.59b, ms., fol. 92r, Op, pág. 183).

Tachada una estrofa entre la 13 y la 14 que hemos podido identificar:

Puesta se ve a sus pies en larga fila

la multitud inmensa de vasallos

desde su real palacio hasta Manila;

¿Quién podrá distinguirlos, ni contallos?

¡Cuánta estraña nación! Cuán varias gentes

de lenguas y costumbres diferentes!

(BAE II, pág.59b, ms. fol. 92v, Op, pág. 184).

\section{Lucrecia}

¿No quieres escucharme?

Espurio [si no es solo mío]

(ms., fol. 86r, OP, pág. 198, I.4, v.72).

\section{Hormesinda}

Después del v.54: "Elvira. Piedad, Infante", último de este acto, siguen 15 versos tachados que no logramos identificar (OP, pág. 209, II.7, ms., fols. 79r y v).

\section{Guzmán el Bueno}

Entre los vv 10 y 11 hay tachados 2 vv:

¿Porque no abrasa un rayo vengativo

a tan infeliz madre? moros fieros

barbaros, inhumanos y crueles

El verso 12 "Moros feroces, bárbaros, crueles" está escrito sobre las tachaduras del v3 (ms. fols 84r y v, OP, pp. 223-224).

Entre los vv.4 y 5 III, 13 hay borrados casi $3 v v$ que podrían corresponder a: ¿Hay dolor semejante? ¡Odiosa vida! 
Variantes significativas que presentan las OP respecto al $\mathrm{ms}$

"Al lector", fol. $3 \mathrm{r}^{12}$.

"Vida del autor"

"En efecto, ni el corrompido gusto del público, ni los anuncios fatales" (OP, pp. XVI-XVII, ms., fol. 8v) ${ }^{13}$.

"Allí se leyó también la Tragedia de Numancia destruida, impresa y representada poco antes" (OP, pág. XXVII, ms., fol. 32v) ${ }^{14}$.

"Y trató de enseñar a los discípulos que quisieran oirle, el camino más florido, aunque el más esteril, de la inmortalidad" (OP, pág. XXXIII, ms., fol. $13 v)^{15}$. $15 v)^{16}$.

"sin embargo, el Duque, hizo empeño particular" (OP, pág. XVI, ms., fol.

Oda El Arroyo (OP, pág. 28, ms., fol. 35v): "Halló las bramadoras/ tempestades terribles,/ cadáveres y tablas" [vv. 21-24] ${ }^{17}$.

Silva Al Conde de Aranda (OP, pág. 31, ms., fol. 36v): "Claro indicio de ti: quando supiste" [v.29]/ "en una y otra hazaña",[v. 30]/ "desordenar falanges poderosas" [v. 69] /"otro ensalce los timbres que engrandecen" [v. 102] ${ }^{18}$.

Romance Abdelcadir y Galiana (OP, pág. 38, ms., fol. 39v): "dos cristianos curan de ella" [v.74] $]^{19}$.

Oda Amor aldeano (OP, pág. 47, ms., fol.43r): "agradecida" [v.31 $]^{20}$.

Soneto Modestia de Dorisa (OP, pág. 54, ms., fol. 46r): "ni hay voz que diga lo que el alma entiende" [v. 14] $]^{21}$. $45]^{22}$.

Oda Nido de Amor (OP, pág. 58, ms., fol. 47v): "La boca fragante" [v.

Silva Al Infante D.Gabriel de Borbón (OP, pág. 58, ms., fol. 47v): "o la lira dulcísima de Orfeo" [v. 6 $]^{23}$.

Canción A d. Pedro Napoli Signorelli (OP, pág. 74, ms., fol. 54r): "a fin de que el olvido" [v. 46]/ "no su gloria consuma" [v. 47] $]^{24}$.

12. corr. Advertencia.

13. público] pueblo.

14. leyó] leyó en última apelación; también] om.

15. más florido, aunque el] $\mathrm{om}$.

16. sin embargo] no obstante.

17. bramadoras] tronadoras.

18. supiste] te vieron; en] con; desordenar] disipar sus; timbres] corr. ileg.

19. corr. dos versos ileg.

20. de agradecida.

21. corr. ileg. 
Soneto El escarmiento (OP, pág. 173, ms., fol. 72r): "Mire qual premio el fiero Amor me ha dado" [v. 14] $]^{25}$.

La Diana. Poema Didáctico (OP, pág. 175, ms. fol., 88r): “Origen de la Caza, Variedad de Fieras"26. v. 102 "en justo imperio las soberbias gentes" pág. $185^{27}$.

Lucrezia II-7 (fol. 87v): como aquel noble egército famoso ${ }^{28}$.

\section{BIBLIOGRAFÍA}

AA.VV. 1980. Revista de Literatura, 84. tomo XLII. Número monográfico dedicado a Nicolás Fernández de Moratín.

AGUILAR PIÑAL, Francisco. 1983. Bibliografía de autores españoles del Siglo XVIII, III, Madrid, CSIC, pp. 342, 406.

ANDIOC, René. (ed.) 1973. Epistolario de L.F.M., Madrid, Castalia.

- (ed.) 1968. Diario (Mayo 1780-1808). Madrid, Castalia.

BBMM. Personalidades de las letras españolas, correspondencia de los siglos XVIII al $X X, 18-9-1$ (II), ms. 108.

CASO GONZÁLEZ, José Miguel. 1980 "De la Academia del Buen Gusto a Nicolás Fernández de Moratín", Revista de Literatura, 84, pp. 5-18.

COTARELO, Emilio. 1897. Iriarte y su época, Madrid, Sucesores de Rivadeneyra, pp. 47-48, 84-85, 94-96.

- BBMM. Carta manuscrita, sin fecha. Escrita entre el 3.X.1913 y el 27.I.1936, período en que Cotarelo fue Secretario perpetuo de la Academia, y su muerte.

DOWLING, John. 1977. "El texto primitivo de Las naves de Cortés destruidas de Nicolás Fernández de Moratín", Boletín de la Real Academia Española, LVII, pp. 431-483.

FERNÁNDEZ DE MORATÍN, Leandro. 1779. La toma de Granada por los Reyes Católicos D. Fernando y $D^{a}$ Isabel. Romance endecasílabo impreso por la Real Academia española por ser entre todos los presentados el que más se acerca al que ganó el premio. Su autor, D. Efrén de Lardnaz y Morante, Madrid, Joachín Ibarra.

- 1825. Obras dramáticas y líricas de D. Leandro Fernández de Moratín, entre los Arcades de Roma Inarco Celenio. Unica edición reconocida por el autor, $\mathrm{Pa}$ rís, Augusto Bobée, III, pp. 454-455.

- 1830-1831. Obras de D. Leandro Fernández de Moratín dadas a la luz por la Real Academia de la Historia, 4 tomos en 6 vols., Madrid, Aguado

22. fragante] corr. ileg.

23. corr.] o la traiciona del Othirsio Orfeo.

24. a fin de que] para que no; no su gloria] sus méritos.

25. cor.] que todo esto vi yo, y me hablé engañado.

26. Arte de la Caza /Poema Didáctico; Origen y progresos.

27. corr.: con blando freno las soberbias gentes.

28. como] sino 
- 1867. Apuntaciones sueltas de Ingleterra en Obras Póstumas de D. Leandro F. de Moratín publicadas de orden y a expensas del Gobierno de S. M., Madrid, Rivadeneryra, I, pp. 161-268.

- [1867] 1991. Viage a Italia. Edición crítica de Belén Tejerina, Madrid, Espasa Calpe.

FERNÁNDEZ DE MORATÍN, Nicolás. 1764. El Poeta. Libro primero. Su autor Don Nicolás Fernández de Moratín, criado de la Reyna Madre, nuestra Señora, entre los Arcades de Roma: Flumisbo Thermodonciaco, Madrid, s.i. Está formado por 10 números, $160 \mathrm{p} p$.

- 1779. "A las niñas premiadas por la Sociedad económica de Madrid en la distribución de 1779" en Noticias de los premios distribuidos a las discípulas de las quatro escuelas patrióticas de Madrid, Madrid, Joachín Ibarra, pp. 3-19. Reproducido en Obras de don Nicolás y don Leandro Fernández de Moratín. Biblioteca de Autores Españoles, 2, pp. 27-31.

- 1785. Las naves de Cortés destruidas. Canto épico. Obra pósthuma de don Nicolás Fernández de Moratín, ilustrada por el editor con varias reflexiones críticas para instrucción de la juventud, Madrid, Imprenta Real. El Canto se anunció en la Gazeta de Madrid del 1 de noviembre de ese mismo año.

- 1821. Obras Póstumas de D. Nicolás Fernández de Moratín. Entre los Arcades de Roma: Flumisbo Thermodonciaco, Barcelona, Imprenta de la Viuda de Roca.

- 1825. Obras póstumas de don Nicolás Fernández de Moratín, entre los Arcades de Roma Flumisbo Thermodonciaco. Segunda edición, conforme en todo a la original publicada en Barcelona en 1821, Londres, Imprenta española de M. Calero.

FERNÁNDEZ DE MORATÍN, Nicolás y Leandro. 1884. Obras de Don Nicolás y Don Leandro Fernández de Moratín, Madrid, Ed. Rivadeneyra, Biblioteca de Autores Españoles, 2.

FLORES Y LA BARRERA, José Miguel de. 1763. "Reseña de Lucrecia" Aduana crítica, Madrid, Imprenta de Gabriel Ramírez, II, pp. 99, 128.

FOULCHÉ-DELBOSC, Raymond. 1892. Poesías inéditas de D. Nicolás Fernández de Moratin, Madrid. s.e.

FUENTE BALLESTEROS, Ricardo de la. 1988. "Dos cartas de Leandro Fernández de Moratín”, Revista de Literatura, 99, pp. 207-210.

GIES, David Thatcher. 1980. Nicolás Fernández de Moratín, Boston, Twayne.

LÁZARO CARRETER, Fernando. 1953. "La transmisión textual de "Fiesta de toros en Madrid", Clavileño, 4, pp. 33-38.

MÉNENDEZ Y PELAYO, Marcelino. 1940. Historia de las ideas estéticas, Madrid, CSIC III, pág. 294, n.

NAPOLI SIGNORELLI, Pietro. 1787-1790. Storia critica de' teatri antichi e moderni, 6 vols., Nápoles. s.e. Vol. VI, pp. 8-11. La primera ed. Nápoles, 1777 y una $3^{ \pm}$ed. Nápoles 1813. EI nombre de Leandro Moratín figura entre los suscritores al tomo III de 1788 .

QUINTANA, Manuel José. 1867. "Sobre la poesía castellana del siglo XVIII" en Obras completas, Madrid. Biblioteca de Autores Españoles, 19, pág. 148. 
[RODRÍGUEZ PORRERO, Claudio]. Catálogo de las cartas y demás documentos autógrafos que componen la colección de Claudio Rodríguez Porrero, BBMM, fols. $1-3$.

[-] Colección de autógrafos, pensamientos, poesía lírica y dramática. Siglos XVIII al XX, BBMM 17/9/1 (I), ms. 787, fol. 40.

[-]. Comentarios y referencias publicadas en libros, revistas y periódicos sobre la colección de autógrafos de don Claudio Rodríguez Porrero, BBMM, 27/7/1.

RODRÍGUEZ DE RIVAS, Mariano s.f. "Autógrafos de artistas españoles", Revista española de Arte [sin fecha].

RODRÍGUEZ SÁNCHEZ DE LEÓN, María José. 1986. "Notas sobre los problemas textuales de los poemas de Leandro Fernández de Moratín premiados por la Academia española", Revista de Literatura, 96, pp. 441-446.

SÁNCHEZ MARIANA, Manuel. 1986. "Los manuscritos de Leandro Fernández de Moratín en la Biblioteca Nacional", en Homenaje a Pedro Sainz Rodríguez, Madrid, Fundación Universitaria Española, pp. 205-223.

SEMPERE Y GUARINOS, José. 1785-1786. Ensayo de una biblioteca española de los mejores escritores del reynado de Carlos III, Madrid, Imprenta Real, I, pág.63.

SIMÓN DÍAZ, José. 1944. "Don Nicolás F. de Moratín, opositor a cátedra", Revista de Filología Española, XXVIII,pp. 154-177, en especial: pp. 157-163, 172-174.

VACA DE GUZMÁN, José María. 1778. Las naves de Cortés destruidas. Canto premiado por la Real Academia Española en junta que celebró el día 13 de agosto de 1778. Su autor D. Joseph María Vaca de Guzmán, Madrid, Joaquín Ibarra.

- 1787. Advertencias que hace a los críticos humanistas y principalmente a los poetas, Don Joseph María Vaca de Guzmán, autor del Canto Las naves de Cortés destruidas, único premiado, y publicado por la Real Academia Española en el año de 1778, primero de este establecimiento, sobre el que con igual objeto y título se ha dado a luz en el de 1785, obra póstuma de D. Nicolás Fernández de Moratín, cotejo, y tácita decisión en órden al mérito de ambas piezas, que apunta el Editor de la segunda en su Prólogo, Alcalá, Imprenta de D. Pedro López. 